\title{
Consumption Value of Digital Devices: An Investigation through Facebook Advertisement
}

\author{
Abhishek Mishra \\ Indian Institute of Management, Prabandh Shikhar, Indore, India \\ Email: abhishek@iimidr.ac.in \\ Received 6 May 2015; accepted 29 June 2015; published 2 July 2015 \\ Copyright (C) 2015 by author and Scientific Research Publishing Inc. \\ This work is licensed under the Creative Commons Attribution International License (CC BY). \\ http://creativecommons.org/licenses/by/4.0/

(c) (i) Open Access

\section{Abstract}

Data collection represents the most effort-intensive stage of any marketing research exercise, especially in cases sampling frame is unavailable. Sub-optimal bypasses in form of student surveys or surveys employing convenience sampling have become common. In modern era, where laptops and smartphones enable easy accessibility of respondents online, this study utilizes Facebook advertisement as a source of data collection to measure the construct of user experience for interactive products. Modern digital devices, like smartphones, are a source of a variety of experiences for the user. Design teams at various smartphone manufacturers are struggling every day to create products which provide complete consumer experiences. This work not only proposes a framework for describing the same with usability, social value and pleasure in use, but also tests the scales for each by empirical validation. Data collection process through Facebook, as a sample frame, is something yet to be seen in marketing literature. This work goes the distance in not only demonstrating the efficacy of using Facebook advertisement as a viable data collection tool but also developing a framework to measure consumption value. Outcomes of the study, should promote further research using this sampling frame for future research, especially in the area of marketing.

\section{Keywords}

Smartphone, Digital Device, Facebook Advertisement, Consumption Value, Usability, Social Value, Pleasure in Use

\section{Introduction}

Every product is a source of experience for the user. The traditional TAM model [1] emphasizes how perceived 
usefulness and perceived ease of use are precursors to prolonged usage of a product by the user. In other words, positive user experience has a long term effect on the intention of a consumer to keep using a belonging. However, contemporary marketing literature is yet to see an empirically valid scale to measure that experience, especially for digital interactive devices. Consequently, we make an endeavor to understand and develop a framework underlining consumption value framework for technology based devices like smartphones. Like any other products, smartphones, too, not only delivers utilitarian benefits in form of functionality but also generates usage pleasure and enjoyment [2]-[4]. As a special category of product performing vivid roles, it is expected to evoke multi-faceted meanings to consumption experience, beyond the traditional utilitarian-hedonic duality. Extant research on digital devices focuses mostly on creation of interaction designs leading to development of usable systems and establishing technology that is not contingent on a high degree of user expertise [5] [6]. There have been few studies of technology exploring experience-centered design, making the impetus for this investigation to empirically develop a framework for user experience of smartphones [7]. Another interesting aspect of this study lies in the way data being collected. With no readily sample frame available for interactive devices like smartphones for probabilistic sampling, Facebook was chosen as a source of real consumers of smartphones. Thus, instead of relying on students' sample using convenience sampling as a way out, we executed our data collection through Facebook, in the process demonstrating efficacy of Facebook Advertisement for quick recruitment in a cost effective way [8].

Extant research on consumption of technology based products remains trapped in the hedonic-utilitarian benefit paradigm operationalized through perceived ease of use and usefulness framework [1]. This study aims to develop a new consumption value framework for digital devices like smartphones. Additionally, the study used social media platform in form of Facebook for randomized data collection using Facebook Advertisement, something yet to be seen in extant marketing literature. Thus, in a nutshell, the research objectives of the study are twofold:

1. Develop and validate a framework for user experience

2. Demonstrate the efficacy of Facebook Advertisement as a source for data collection.

\section{User Experience Framework}

Literature on customer experience has been explored through two approaches: Emotion approach [9] and Customer value approach [10]. In the first approach, customers' emotions are the mainstay of conceptualizing experience, while in the latter, customers' perceived value is the central point of customers' perceived experience. According to Holbrook, the exploration of the customer experience actually builds a path to insights into the concept of customer value. Holbrook (1999) defined customer value as an interactive relativistic preference experience, emphasizing that customer experiential approach actually examines the customer value that is attached to the consumption [11]. This means that in order to create customer experience, it is important to identify customer value. In contextual literature, experiential value is considered as a customer's perception based upon interactions involving either direct usage or distanced appreciation of goods and services [10]. These interactions provide the basis for the relativistic preferences held by the individuals involved (Holbrook, 1999) [11]. He has described four typologies of the experiential value dimensions, which has been reiterated by Boztepe (2003) as: 1) Utilitarian Value referring the way a product helps achieving practical ends; 2) Social Value as product's instrumentality in achieving certain social objective, such as affirmation of a social status; 3) Emotional Value as the benefit of a product in terms of the emotions it provokes; and finally; 4) Altruistic Value as the sense of a being right or good (p. 6) [12]. In a recent work, Kim, Kim and Wachter (2013) highlighted three motivations for people underlying the adoption and usage of smartphones — utilitarian, social and hedonic [13]. While the motivations themselves were adopted in a cognition-affective-conative framework rooted in the attitude theory, they are a near overlap to the three motivations with the three experiential values by Holbrook (1999) [11]. This work proposes the following experiential values, arrived after congregating similar works in literature combined with enhanced meaning.

\subsection{Usability}

The concept of usability is well embedded in the theory of affordances with Norman (1988) urging designers to make products intuitive [14]. The construct of usability derives its meaning from cognitive attitude of Rosenberg's tripartite attitude theory and utilitarian value in the context of theory of experiential consumption. From the theory of planned behavior vantage point, usability ensures higher perceived behavioral control making the user interact with the device more frequently and fluently, as well as assuring user confidence in one's cognitive abilities in turn making product use a pleasurable experience [15]. Nielsen (1993) defines usability in terms of five attributes: 
efficiency, learnability, memorability, errors and satisfaction [16]. These definitions imply that usability is a broader construct, subsuming the two critical concepts of perceived ease of use and perceived usefulness as a measure of functional value [17]. Earliest introduction to the concept came from Eason (1984) [18] and Shackel (1986) [19]. Usability has always been studied in literature from computer systems point of view and is considered to be a core requisite of satisfaction from consumption experience [3]. While human-computer interaction (HCI) researchers strive to create usability using usability engineering and usability testing, the litmus test is faced by the actual product by another set of consumers in real usage situation, determining the success of a product design.

\subsection{Social Value}

Also referred to as sociability benefit [20], this is the second value which accrues to the user because of possession of a particular product [11] [21]. Apart from diverse design configurations of their elements, products portray peoples' values and personality and, thus, help showcase social status, as envisage in the social cognitive theory [22]. For any product, ownership is an aftermath of the motivation for seeking social identity and value systems clubbed with socio-psychological benefits, implying belongingness to relevant social and professional groups [23]. In that light, Hassenzahl (2004) [24] identifies the concept of identification as one of the functions of a product which implies expressing one's self through that. This function of self-presentation through an object is an indicator of social value and enables an individual to be seen and interpreted in a certain way by relevant members of the society, as a feedback mechanism. Literature on product symbolism led by Solomon (1983) [25] argues that every product has a meaning which not only defines the relation between the product and owner, but also regulates the empathy of the user to relevant others [26]. This is also supported by Crilly et al. (2004) [27], who present an integrated framework to describe two major qualities of product design: 1) Semantic interpretation as a message about the product user by way of its functions or mode of use 2) Symbolic Association related to what the product says about the owner rather than itself [28]. Both, in a certain way, add to the social value for the user.

\subsection{Pleasure in Use}

Pleasure of Usage drives the hedonic value of a product [29] in the theory of experiential consumption. They state that enjoyment of using a likable product gives an intrinsic sense of satisfaction leading to feelings of fun and excitement. As a well-researched value derived in product use, pleasure in use forms the third important experiential value in our framework. The concept of usage pleasure or flow stems from the affective attitude component of the attitude theory, causing consumers to evoke emotions in usage setting. Relying on experiential consumption theory, Jordan (1998) believes that it's not necessary for a usable product to be pleasurable or vice versa [3]. This argument concurs with the value framework developed by Holbrook (1999) [11] and Sheth, Norman and Gross (1991) [21]. This is also referred to as soft functionality of a product referring to emotional aspects that defines the relationship of a user with a product [30]. The ability of a product to create emotion or affect in the user has gained tremendous attention in literature, specially recently in the grounded theory of design value [31]. Design literature has seen manifestation of emotion in various forms - experiential needs [32], affective responses [33], emotional benefits [34] and pleasure [35]. A product through its semantic expression, creates association with the user and thus leads to emotional value, revealed well in Hassenzahl's (2004) statement: "Using a product with a particular product character in a particular situation will lead to consequences, such as emotions (e.g. pleasure)" (p. 322) [24]. The root of this concept lies in Jordan (1998) [3] defining pleasure "during” usage as emotional and hedonic benefits associated with a product consumption, with Coelho and Dahlman (2000) [36] considering displeasure as emotional and hedonic penalties. It is, thus, evident that emotions have a heavy role to play in measuring the derivation of pleasure in usage by a consumer. We undertake the three constructs of usability, social value and pleasure in use as ones that can comprehensively measure consumption experience. Next, we demonstrate the process of validating the scales for three constructs as well as how Facebook Advertisement served as tool to collect data for achieving that goal.

\section{Methodology}

The study adopts standard scales for measurements of the three manifestations of consumption experience. Table 1 presents the scale to be used for measuring each of them. Appendix A highlights the items for the each of the scale. 
Table 1. Constructs and scales.

\begin{tabular}{cccc}
\hline Measure & Construct & Scale to be Used & Scale details \\
\hline $\begin{array}{c}\text { User Experiential Value } \\
\text { (Holbrook, 1999) }\end{array}$ & Usability & Brooke (1986) & 10 item scale (each 5 point agree/disagree \\
& Social Value & Sweeney and Soutar (2001) & 4 item scale (each 5 point agree/disagree) \\
\hline
\end{tabular}

An online descriptive questionnaire was constructed based on these items. The target group for the study was all those people who own smartphones. Smartphone is defined as special category of mobile phones which are more capable than feature phones in terms of performance and multi-tasking and more specifically can run third party applications. The following info graphic (Figure 1) represents the India Smartphone penetration as per Vserve (2013) [37].

According to Smartphone Insights report of both Nielsen Informate (2012) [16] as well as that of Vserve (2013) [37], maximum smartphone penetration lies in the top 4 metros (accounting for $45 \%$ of all smartphones in India) as well as age groups under 45 years. On the basis of this report, we targeted people living in the top 4 metrosDelhi, Mumbai, Chennai and Kolkata in specific age groups as depicted in the info-graphic above. Straightaway, the problem faced was that there is no sampling frame (population of people having smartphones) available. This problem also plagues the two syndicate studies mentioned above, which resorted to convenience sampling with larger sample sizes for their findings. To circumnavigate our way around this constraint, we chose a different source of information rarely used in contemporary research—Facebook. The logic for choosing Facebook lies in the fact that $93 \%$ of smartphone owners in India are active on Facebook and hence, it provides a ready access to the population which can be targeted randomly [16]. In the process of targeting people randomly from such a target group, we resorted to stratified sampling. Stratas were formed based on two demographic parameters - city and age group and only those cities and age groups were targeted that represented the heaviest incidence of smartphones, which for our case were the four metros and age groups of below 17 years, 18 - 25 years, 26 - 35 years and 36 - 45 years. The strata were formed in such a way that it covered all the four age groups as well as the four cities depicted in Table 2.

To target each stratum, one Facebook Advertisement was launched for each of them, with a total of four separate advertisements. Each advertisement was unique with different mask but contained a link to the questionnaire hosted on an external website. Users clicking the advertisement on their Facebook profile were taken to the questionnaire site.

\section{How Does Facebook Advertisement Work?}

Facebook Advertisements are targeted according to user's Facebook profile information: age, location, education, relationship status, interests like favorite movies, music and much more aspects which are available to advertisers that can access to aggregate data and reach the right audience for their ads ${ }^{1}$. Depending on their goals and the product that they are advertising, advertisers can set a targeting filter to select which group of people will see their ad. This makes it possible to focus on or target the people most likely to be interested in the product, amongst the more than a billion worldwide Facebook users. What made Facebook Advertisement useful for our study was that Facebook also offers owners of smartphones as a filter in the user profiling section, which means that only those people who own a smartphone are eligible to see the advertisement. The following set of pictures (Figure 2) represent a walkthrough about how to launch a Facebook advertisement.

Once an advertisement is launched, it starts appearing randomly on the profile of a set of people who fall within the target segment as depicted in Figure 3.

There are two modes of targeting available in Facebook, one is Cost per Click (CPC) and other is Cost per Impression (CPM). In the CPC mode, the advertiser is supposed to pay only when a user clicks the ad to go to a hyperlink. However, in case of CPM, the advertiser pays when an impression is made, where impression implies that a particular advertisement appeared on a user profile. The total budget of the advertiser and the money she can spend on a daily basis decided how many of the total targetable population will be exposed to the advertisement on a daily basis randomly. If given enough time and money, the entire population as available on Facebook will be

${ }^{1}$ Facebook Ads Guide; Social Ad Tools; available at: http://www.socialadstool.com/facebook-ads-guide/how-facebook-ads-work/. 


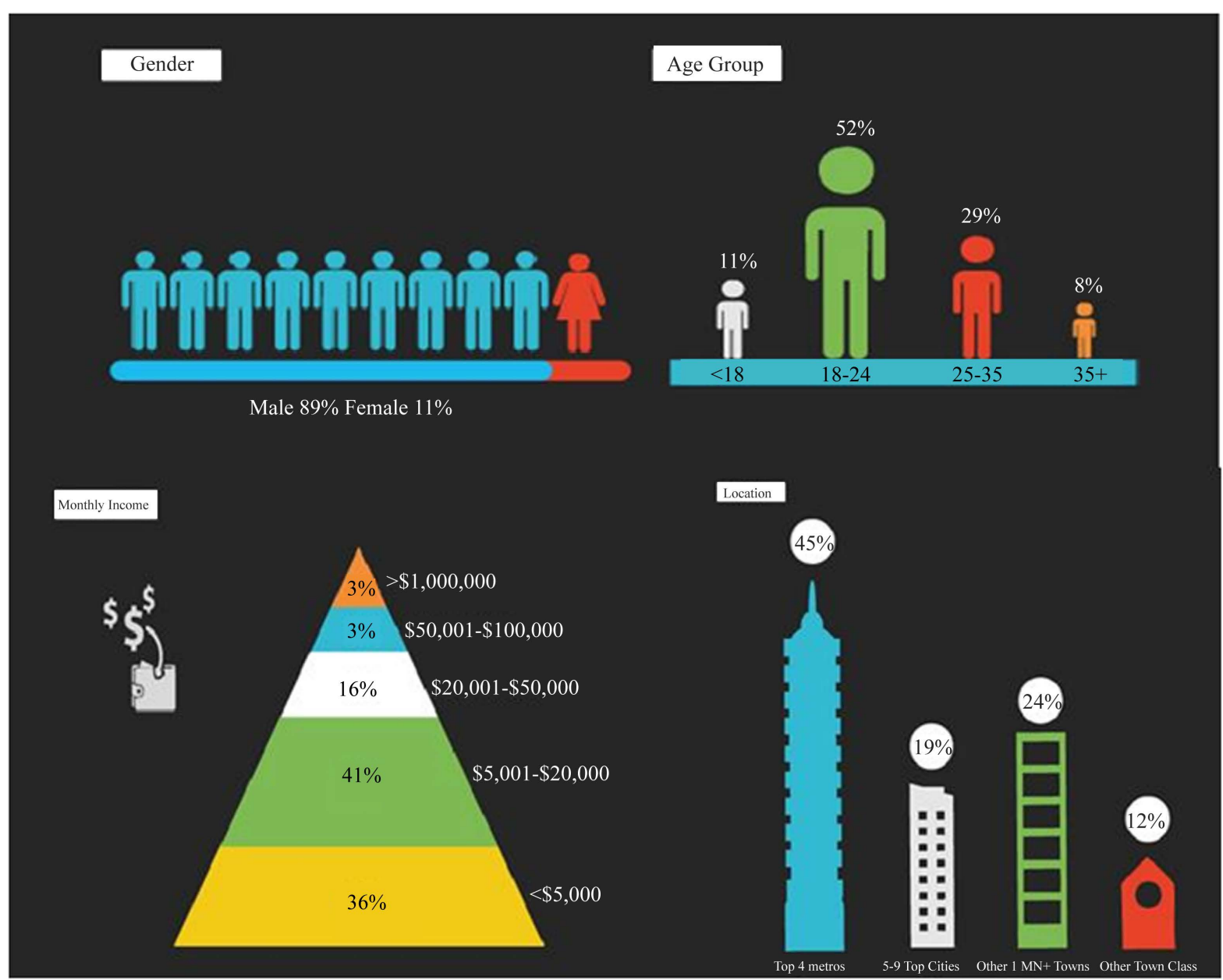

Figure 1. India smartphone insights (Vserve, 2013).

Table 2. Strata for sampling.

\begin{tabular}{c|ccc}
\hline City/Age & Delhi & Mumbai & Chennai \\
\hline Below 17 & & & \\
$18-25$ & & & \\
$26-35$ & & & \\
$36-45$ & & & \\
\hline
\end{tabular}

exposed to the advertisement at least once.

\section{Data Collection}

We secured the financial support of Facebook itself in funding these advertisements and paid a relatively healthy INR 20 per click with a maximum budget of INR 100,000. Facebook Advertisement also reports the total population that is targetable by the advertisement. Based on the number of people available in each stratum as well as accounting for the budget available, proportional sampling of 1 every thousand people was chosen within each stratum. After the proportion was acquired, the Facebook Advertisement was terminated. Figure 4 depicts how the targeting was done and number of responses obtained in each city.

Thus, it is evident that in all 4220 respondents clicked the advertisement across the four strata out of which a total of 1208 completed questionnaires were received, as depicted in Figure 4. The cumulative response rate came out to 


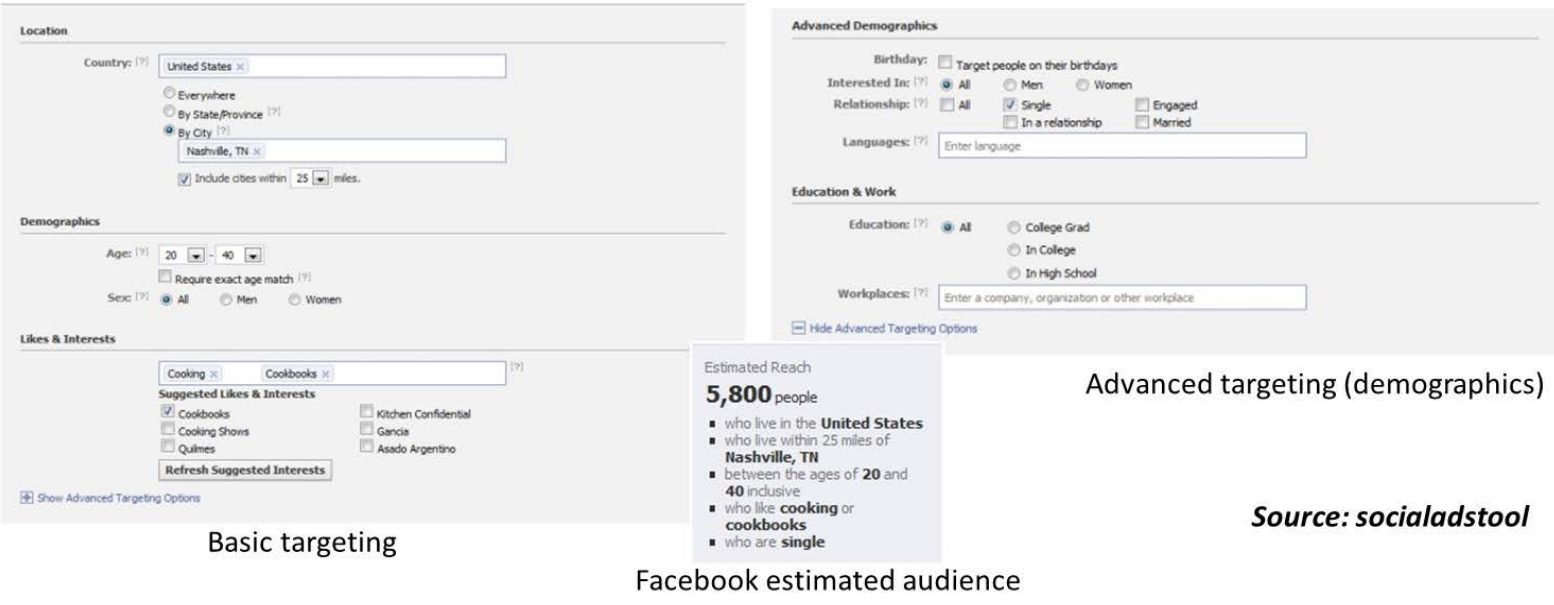

Figure 2. Facebook advertisement walkthrough.

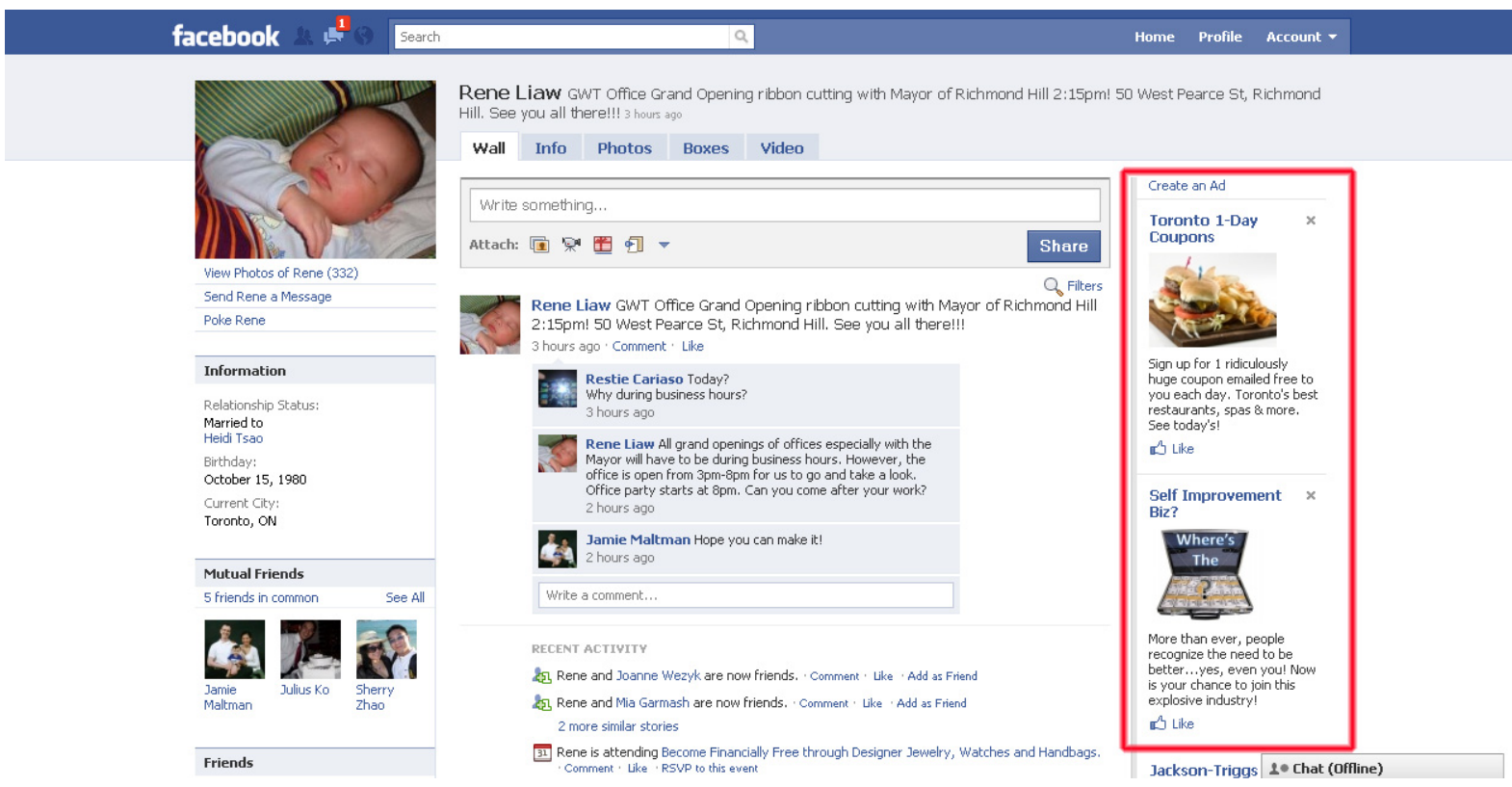

Figure 3. Facebook advertisement on a user profile.

\begin{tabular}{|c|c|c|c|c|}
\hline Town/Age & Delhi & Mumbai & Chennai & Kolkata \\
\hline Under 17 & Facebook Ad 1 & & & \\
\hline $18-25$ & & Facebook Ad 2 & & \\
\hline $26-35$ & & & Facebook Ad 3 & \\
\hline $36-45$ & & & & Facebook Ad 4 \\
\hline Town & Delhi & Mumbai & Chennai & Kolkata \\
\hline Potential Population & $8,60,000$ & $24,00,000$ & $7,40,000$ & $2,20,000$ \\
\hline Targeting & 860 & 2400 & 740 & 220 \\
\hline Responses & 230 & 409 & 471 & 98 \\
\hline Response Rate & $26.7 \%$ & $17.0 \%$ & $63.6 \%$ & $44.5 \%$ \\
\hline
\end{tabular}

Figure 4. Sampling strategy using Facebook. 
be $28.6 \%$ and is fairly close to $34 \%$ average response rate for web surveys, which Shih and Fan (2008) [38] report in their review of 300 such works. Because of 4220 clicks to our advertisements for all the four strata, we ended up spending INR 84,400, a little below the target budget approved by Facebook. It is also clear that that sample size achieved was more than the target set for an effective data analysis. The Facebook Advertisements ran for a period of six months between July 2013 and December 2013. After the questionnaire items had been pretested and items finalized, a primary requirement to maintain construct validity as well as avoid any form of ordering bias, the items were systematically randomized. Since the questionnaire was online, this was an easy task. A premium membership of the site hosting the questionnaire was subscribed, which allowed for randomization of the items in questionnaire using a standard algorithm. Though the option of randomization of pages was also available, it was not availed as that would have disturbed the flow of the questionnaire. The following Table 3 presents the detailed sample breakup finally achieved:

\section{Results}

On the data, initially, underlying factor structure was analyzed using exploratory factor analysis (EFA). SPSS was used of this purpose. Factor loadings of each item with a factor were used as a benchmark for construct integrity as represented in Table 2. After EFA, misbehaving items, whose factor loadings were less than 0.4 [39] and severe cross loadings, were dropped from further analysis. Next, confirmatory factor analysis (CFA) was done using AMOS to establish reliability and validity of the items used for each construct (Table 4).

As is evident, the fit measures are adequate as per Hu and Bentler's (1999) [40] recommendations. The following Table 5 demonstrates the test for reliability and validity of the constructs.

The measures for usability, social value and pleasure in use have sufficient reliability with both composite reliability and cronbach alpha greater than 0.70 . Further, since average variance extracted (AVE) values for all the constructs are greater than 0.50 , we have sufficient convergent validity. Finally, we also see that none of the AVE

Table 3. Sample characteristics.

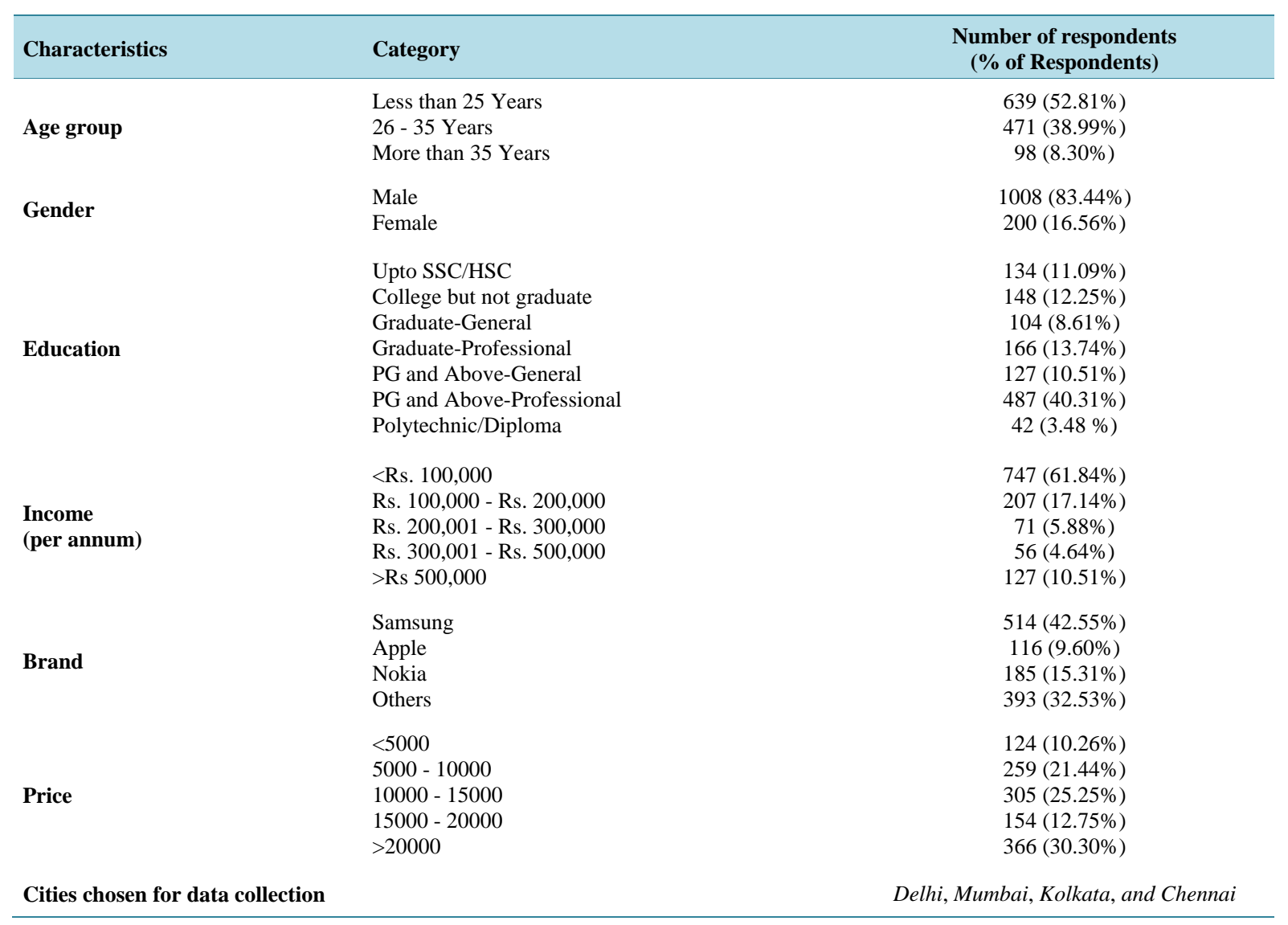


Table 4. EFA and CFA results.

\begin{tabular}{|c|c|c|c|c|c|c|}
\hline \multirow{2}{*}{ Item } & \multicolumn{3}{|c|}{ EFA } & \multicolumn{3}{|c|}{ CFA } \\
\hline & Usability & Social Value & Usage Pleasure & Usability & Social Value & Usage Pleasure \\
\hline US1 & 0.70 & & & 0.53 & & \\
\hline US2 & 0.82 & & & 0.78 & & \\
\hline US3 & 0.66 & & & 0.67 & & \\
\hline US4 & $0.33^{*}$ & & & & & \\
\hline US5 & $0.27^{*}$ & & & & & \\
\hline US6 & $0.38^{*}$ & & & & & \\
\hline US7 & 0.73 & & & 0.70 & & \\
\hline US8 & $0.39 *$ & & & & & \\
\hline US9 & $0.21^{*}$ & & & & & \\
\hline US10 & $0.32 *$ & & & & & \\
\hline SV1 & & 0.77 & & & 0.76 & \\
\hline SV2 & & 0.85 & & & 0.84 & \\
\hline SV3 & & 0.88 & & & 0.90 & \\
\hline SV4 & & 0.86 & & & 0.85 & \\
\hline PU1 & & & 0.54 & & & 0.80 \\
\hline PU2 & & & 0.72 & & & 0.80 \\
\hline PU3 & & & 0.69 & & & 0.84 \\
\hline PU4 & & & 0.65 & & & 0.84 \\
\hline PU5 & & & 0.77 & & & 0.88 \\
\hline
\end{tabular}

CFA: Chi-Sq = 711.6 (df = 62); GFI: 0.92; IFI: 0.94; CFI: 0.94; TLI: 0.92; RMSEA = 0.09; RMR $=0.06$.

Table 5. Reliability and validity check.

\begin{tabular}{cccccc}
\hline Variable & AVE & CR & Cronbach Alpha & \multicolumn{2}{c}{ Squared Correlation } \\
\hline Usability & 0.59 & 0.85 & 0.79 & - & SV \\
Social Value & 0.81 & 0.94 & 0.92 & 0.06 & 0.35 \\
Usage Pleasure & 0.78 & 0.95 & 0.93 & - & 0.42 \\
\hline
\end{tabular}

values is less than any of the squared correlation values for a constructs, thus establishing discriminant validity as well.

\section{Conclusion}

Organizations manufacturing digital devices are fighting hard to create unique and positive user experiences for the consumer. A complete experience habituates the user to the product so that they are ready to pay even premium prices to obtain the product next time. In a novel approach, this study aims to empirically establish a framework to measure such user experience. The study adopted Holbrook's framework of consumption values to propose three components of user experience relevant to a smartphone-usability, social value and pleasure in use. An extensive analysis proved that the three components adequately measure consumption experience with sufficient reliability 
and validity. Not only does the study provide a new framework for measuring user experience, but also tests the items for usage as a scale for future such studies. For managers, the study establishes that to provide great experience, it is important not only to increase usability but also to design a product such that it provides social status to the user ultimately leading to usage pleasure.

From a methodological perspective, a contribution lies in usage of Facebook as a medium of data collection which we do not come across in a marketing study so far. The study demonstrates how Facebook can be a suitable repository of respondents which can be targeted randomly by virtue of the Facebook Advertisement algorithm. Our work, thus, prods the way for future researchers to use this highly resourceful database to complete data collection in a quick turnaround time. A possible drawback with Facebook lies in the limitation of choosing people with specific demographic profiles and interests. If a study involves a target profile of a respondent which cannot be filtered by Facebook Advertisement, the methodology is rendered untenable. Further, Facebook is a personal space for users who are least interested in watching and clicking on advertisements lying in the corner of their profile page. This might lead to really poor response rates unless there are goodies on offer for them.

\section{References}

[1] Davis, F.D. (1989) Perceived Usefulness, Perceived Ease of Use, and User Acceptance of Information Technology. MIS Quarterly, 13, 319-339. http://dx.doi.org/10.2307/249008

[2] Cyr, D., Head, M. and Ivanov, A. (2006) Design Aesthetics Leading to M-Loyalty in Mobile Commerce. Information and Management, 43, 950-963. http://dx.doi.org/10.1016/j.im.2006.08.009

[3] Jordan, P.W. (1998) Human Factors for Pleasure in Product Use. Applied Ergonomics, 29, 25-33. http://dx.doi.org/10.1016/S0003-6870(97)00022-7

[4] Jordan, P.W. (2000) Designing Pleasurable Products: An Introduction to the New Human Factors. Taylor and Francis, London.

[5] Harper, K. (2001) Environment as Master Narrative: Discourse and Identity in Environmental Conflicts (Special Issue Introduction). Anthropological Quarterly, 74, 101-103. http://dx.doi.org/10.1353/anq.2001.0027

[6] Helyar, V. (2002) Usability of Portable Devices: The Case of WAP. In: Brown, B., Green, N. and Harper, R., Eds., Wireless World, Springer, London, 195-206.

[7] Battarbee, K. (2003) Defining Co-Experience. Proceedings of the 2003 International Conference on Designing Pleasurable Products and Interfaces, New York, 23-26 June 2003, 109-113. http://dx.doi.org/10.1145/782896.782923

[8] Kapp, J.M., Peters, C. and Oliver, D.P. (2013) Research Recruitment Using Facebook Advertising: Big Potential, Big Challenges. Journal of Cancer Education, 28, 134-137. http://dx.doi.org/10.1007/s13187-012-0443-z

[9] Westbrook, R.A. and Oliver, R.L. (1991) The Dimensionality of Consumption Emotion Patterns and Consumer Satisfaction. Journal of Consumer Research, 18, 84-91. http://dx.doi.org/10.1086/209243

[10] Mathwick, C., Malhotra, N. and Rigdon, E. (2001) Experiential Value: Conceptualization, Measurement and Application in the Catalog and Internet Shopping Environment. Journal of Retailing, 77, 39-56. http://dx.doi.org/10.1016/S0022-4359(00)00045-2

[11] Holbrook, M. (1999) Consumer Value: A Framework for Analysis and Research. Routledge, New York. http://dx.doi.org/10.4324/9780203010679

[12] Boztepe, S. (2003) The Notion of Value and Design. Journal of Asian Design International Conference, Institute of Art and Design, University of Tsukuba, Tsukuba, October 2003, 1-10.

[13] Kim, Y.H., Kim, D.J. and Wachter, K. (2013) A Study of Mobile User Engagement (MoEN): Engagement Motivations, Perceived Value, Satisfaction, and Continued Engagement Intention. Decision Support Systems, 56, 361-370. http://dx.doi.org/10.1016/j.dss.2013.07.002

[14] Norman, D.A. (1988) The Design of Everyday Things. The MIT Press, Cambridge.

[15] Wigfield, A., Tonks, S. and Klauda, S.L. (2009) Expectancy-Value Theory. Handbook of Motivation at School, 55-75.

[16] Nielsen (2012) Smartphone Insights Report. http://www.nielsen.com/in/en/press-room/2012/smartphone-incidence.html

[17] Sheng, M.L. and Teo, T.S.H. (2012) Product Attributes and Brand Equity in the Mobile Domain: The Mediating Role of Customer Experience. International Journal of Information Management, 32, 139-146. http://dx.doi.org/10.1016/j.ijinfomgt.2011.11.017

[18] Eason, K.D. (1984) Towards the Experimental Study of Usability. Behavior and Information Technology, 3, $133-145$. http://dx.doi.org/10.1080/01449298408901744 
[19] Shackel, B. (1986) Ergonomics in Design for Usability. In: Editor, Ed., People and Computers, Cambridge University Press, Cambridge, pp.

[20] Leung, L. and Wei, R. (2000) More than Just Talk on the Move: Uses and Gratifications of the Cellular Phone. Journalism and Mass Communication Quarterly, 77, 308-321. http://dx.doi.org/10.1177/107769900007700206

[21] Sheth, J.N., Newman, B.I. and Gross, B.L. (1991) Why We Buy What We Buy: A Theory of Consumption Value. Journal of Business Research, 22, 159-170. http://dx.doi.org/10.1016/0148-2963(91)90050-8

[22] Seva, R.R. and Helander, M.G. (2009) The Influence of Cellular Phone Attributes on Users' Affective Experiences: A Cultural Comparison. International Journal of Industrial Ergonomics, 39, 341-346. http://dx.doi.org/10.1016/j.ergon.2008.12.001

[23] Petruzzellis, L. (2010) Mobile Phone Choice: Technology versus Marketing. The Brand Effect in the Italian Market. European Journal of Marketing, 44, 610-634. http://dx.doi.org/10.1108/03090561011032298

[24] Hassenzahl, M. (2004) The Interplay of Beauty, Goodness, and Usability in Interactive Products. Human-Computer Interaction, 19, 319-349. http://dx.doi.org/10.1207/s15327051hci1904_2

[25] Solomon, M.R. (1983) The Role of Products as Social Stimuli: A Symbolic Interactionist Perspective. Journal of Consumer Research, 10, 319-329. http://dx.doi.org/10.1086/208971

[26] McDonagh, D., Bruseberg, A. and Haslam, C. (2002) Visual Product Evaluation: Exploring Users' Emotional Relationships with Products. Applied Ergonomics, 33, 231-240. http://dx.doi.org/10.1016/S0003-6870(02)00008-X

[27] Crilly, N., Moultrie, J. and Clarkson, P.J. (2004) Seeing Things: Consumer Response to the Visual Domain in Product Design. Design Studies, 25, 547-577. http://dx.doi.org/10.1016/j.destud.2004.03.001

[28] Seva, R.R., Duh, H.B.L. and Helander, M.G. (2010) Structural Analysis of Affect in the Pre-Purchase Context. DLSU Business and Economics Review, 19, 43-52. http://dx.doi.org/10.3860/ber.v19i2.1472

[29] Holbrook, M.B. and Batra, R. (1987) Assessing the Role of Emotions as Mediators of Consumer Responses to Advertising. Journal of Consumer Research, 14, 404-420. http://dx.doi.org/10.1086/209123

[30] McDonagh, D. and Lebbon, C. (2000) The Emotional Domain in Product Design. Design Journal, 3, 31-43. http://dx.doi.org/10.2752/146069200789393562

[31] Noble, C.H. and Kumar, M. (2010) Exploring the Appeal of Product Design: A Grounded, Value-Based Model of Key Design Elements and Relationships. Journal of Product Innovation Management, 27, 640-657. http://dx.doi.org/10.1111/j.1540-5885.2010.00742.x

[32] Holbrook, M.B. and Hirschman, E.C. (1982) The Experiential Aspects of Consumption: Consumer Fantasies, Feelings and Fun. Journal of Consumer Research, 9, 132-140. http://dx.doi.org/10.1086/208906

[33] Derbaix, C.M. and Pham, M.T. (1991) Affective Reactions to Consumption Situations: A Pilot Investigation. Journal of Economic Psychology, 12, 325-355. http://dx.doi.org/10.1016/0167-4870(91)90019-P

[34] Desmet, P., Tax, S. and Overbeeke, K. (2000) Designing Products with Added Emotional Value: Development and Application of an Approach for Research through Design. The Design Journal, 4, 32-47. http://dx.doi.org/10.2752/146069201789378496

[35] Jordan, P.W. and Servaes, M. (1995) Pleasure in Product Use: Beyond Usability. In: Robertson, S., Ed., Contemporary Ergonomics, Taylor and Francis, London, 341-346.

[36] Coelho, D.A. and Dahlman, S. (2000) Comfort and Pleasure. In: Jordan, P.W. and Green, B., Eds., Pleasure in Product Use, Taylor and Francis, London, 321-331.

[37] The Mobile Internet Consumer (2013) Vserve Report. http://www.vserv.mobi/wp-content/uploads/2013/09/Mobile-Internet-Consumer-India.pdf.

[38] Shih, T.H. and Fan, X.T. (2008) Comparing Response Rates from Web and Mail Surveys: A Meta-Analysis. Field Methods, 20, 249-271. http://dx.doi.org/10.1177/1525822X08317085

[39] Tabachnick, B.G. and Fidell, L.S. (2007) Multivariate Analysis of Variance and Covariance. Using Multivariate Statistics. Allyn and Bacon, Boston, 243-310.

[40] Hu, L.T. and Bentler, P.M. (1999) Cutoff Criteria for Fit Indexes in Covariance Structure Analysis: Conventional Criteria versus New Alternatives. Structural Equation Modeling: A Multidisciplinary Journal, 6, 1-55. http://dx.doi.org/10.1080/10705519909540118

[41] Brooke, J. (1986) SUS—A Quick and Dirty Usability Scale. Usability Evaluation in Industry, 189-194.

[42] Sweeney, J.C. and Soutar, G.N. (2001) Consumer Perceived Value: The Development of a Multiple Item Scale. Journal of Retailing, 77, 203-220. http://dx.doi.org/10.1016/S0022-4359(01)00041-0 


\section{Appendix A}

\section{Usability}

\begin{tabular}{|c|c|c|}
\hline Definition & Item & Source \\
\hline $\begin{array}{l}\text { The effectiveness, efficiency and satisfaction with which } \\
\text { specified users can achieve specified goals in particular } \\
\text { environments. Effectiveness is defined as "the accuracy and } \\
\text { completeness with which users achieve specified goals" and } \\
\text { efficiency as "the resources expended in relation to the accuracy } \\
\text { and completeness with which users achieve goals" (IS0 DIS } \\
\text { 9241-11) }\end{array}$ & $\begin{array}{l}\text { I use my phone frequently } \\
\text { I find my phone simple to use } \\
\text { yI can effectively complete my work using my phone } \\
\text { I find my phone easy to learn }\end{array}$ & Brooke (1986) [41] \\
\hline
\end{tabular}

\section{Social Value}

\begin{tabular}{lll}
\hline Definition & Item & Source \\
\hline & My phone makes me feel acceptable in a group \\
$\begin{array}{l}\text { Social Value is the social consequences of what the } \\
\text { product communicates to others (Sweeney and Soutar, }\end{array}$ & $\begin{array}{l}\text { My phone improves the way I am perceived } \\
\text { 2001) [42] }\end{array}$ \\
& My phone makes a good impression on other people $\quad$ [42]
\end{tabular}

\section{Pleasure in Use}

\begin{tabular}{lll}
\hline Definition & Item & Source \\
\hline & My phone always makes me want to use it \\
The utility derived from the feelings or affective states & I feel very relaxed while using my phone \\
$\begin{array}{l}\text { that a product generates (Sweeney and Soutar, 2001) } \\
\text { [42] }\end{array}$ & My phone makes me feel very good \\
& Using this phone gives me great pleasure \\
\hline
\end{tabular}

